\title{
Energy and nitrogen metabolism of rabbits during pregnancy, lactation, and concurrent pregnancy and lactation
}

\author{
BY G. G. PARTRIDGE, G. E. LOBLEY AND R. A. FORDYCE \\ Rowett Research Institute, Bucksburn, Aberdèen AB2 9SB
}

(Received 28 August 1985 - Accepted 29 January 1986) \begin{abstract}
concurrent pregnancy and lactation. applied to the experimental group. $\mathrm{N}$ retention increased in $\mathbf{P}$ and CPL does in late pregnancy. and energy retention (ER; MEI - heat loss) in each physiological state. The equations were:

$$
\begin{aligned}
& \text { NP: } E R=0.67(\text { SE 0.057) } \mathrm{MEI}-208, \\
& \text { P: } E R=0.67(\text { SE 0.095) } \mathrm{MEI}-224, \\
& \text { L: ER }=0.90(\mathrm{SE} \mathrm{0.022)} \mathrm{MEI-441,} \\
& \text { CPL: } E R=0.85(\text { SE 0.036) MEI - 387, }
\end{aligned}
$$
\end{abstract}

1. In an experiment twenty-four cross-bred does were used, six in each of four physiological states: non-pregnant (NP), pregnant (P), lactating (L) or concurrently pregnant and lactating (CPL). They were offered a diet of high nutrient density (crude protein (nitrogen $\times 6.25) 272 \mathrm{~g} / \mathrm{kg}$ dry matter $(\mathrm{DM}$ ), metabolizable energy $15.5 \mathrm{MJ} / \mathrm{kg}$ $\mathrm{DM})$ at one of two intakes on a scale based on metabolic body-weight (kg body-weight $\left.{ }^{0.75}\right)$. The study lasted for $24 \mathrm{~d}$ and was divided into three consecutive $8 \mathrm{~d}$ periods: 'early', 'mid-' and 'late' pregnancy or lactation, or

2. Around the mid-point of each period the does were placed for $24 \mathrm{~h}$ in a gradient-layer calorimeter, and measurements of energy exchange were made. $\mathbf{N}$ balance was also measured throughout each period of the study.

3. Milk output in L and CPL does was measured by weighing the does immediately before and after suckling once each day. Milk samples were taken from a parallel group of does and the estimates of milk composition

4. Milk yields and composition were similar for $L$ and CPL does in early and mid-lactation, but in late lactation the milk output from CPL does declined rapidly. This was the period of maximal fetal growth rates. Energy and

5. Regression analysis was carried out to summarize the relations between metabolizable energy intake (MEI)

where all variables are expressed in $\mathrm{kJ} / \mathrm{kg}$ body-weight $\mathrm{t}^{0.75}$ per $\mathrm{d}$.

The definition of protein and energy requirements for various anabolic processes is a fundamental aim in research on animal production. As interest has grown in the use of the rabbit as a meat-producing species, so has experimental work on the definition of its nutrient requirements for maintenance, growth and reproduction (for reviews, see (US) National Research Council, 1977; Lang, 1981). Although energy requirements for growth to usual slaughter weights $(\sim 2 \cdot 2 \mathrm{~kg})$ are now relatively well defined, there is still a lack of information on the nutritional needs of does during various phases of the reproductive cycle.

The economic viability of commercial rabbit producion in the UK is heavily dependent on the maintenance of a high reproductive rate. In this respect the rabbit has a distinct advantage in that it is one of the few farmed species which has the ability to mate immediately after parturition, implant and thereafter sustain pregnancy concurrent with lactation. Stock of suitable genetic quality is able to sustain concurrent pregnancy and lactation over a number of successive reproductive cycles, when offered diets of high nutrient density. By this means average total outputs of eighty pups born/doe per year have been achieved in a commercial rabbitry (Partridge et al. 1984). There is little information in the literature, however, on the nutritional needs of animals maintained in such intensive breeding systems.

The present study aimed to define more precisely the energy requirements of adult does for maintenance, pregnancy, lactation and concurrent pregnancy and lactation using direct calorimetry. 
Table 1. Diet composition and chemical analysis $(\mathrm{g} / \mathrm{kg})$

\begin{tabular}{ll}
\hline Ingredients & \\
Soya-bean meal & 294 \\
Flaked maize & 227 \\
Barley straw & 165 \\
Full-fat soya-bean meal & 128 \\
White fish-meal & 58 \\
Maize oil & 50 \\
Vitamin mix* & 25 \\
Mineral mix* & 50 \\
D- $\alpha$-Tocopherol (antioxidant) & 0.05 \\
Coccidiostat $\dagger$ & 0.9 \\
'Maxibond', pellet hardener & 3 \\
Analysis (g/kg DM) & \\
Crude protein (nitrogen $\times 6.25)$ & 272 \\
Ash & 87 \\
Acid-detergent fibre & 147 \\
Fat & 97 \\
Gross energy (MJ/kg DM) & 21.46 \\
Predicted ME (MJ/kg DM) & 15.5 \\
\hline
\end{tabular}

DM, dry matter; ME, metabolizable energy.

* For details, see Partridge \& Allan (1982).

† 'Cycostat'; Cyanamid Ltd.

$\ddagger \mathrm{DM}$ content of the diet was $894 \mathrm{~g} / \mathrm{kg}$.

\section{MATERIALS AND METHODS \\ Diets}

A single high-protein, high-energy diet was offered in restricted amounts throughout the present study. Its composition and chemical analysis are shown in Table 1. All animals had been offered this diet for at least $14 \mathrm{~d}$ before the experiment began.

\section{Animals}

Twenty-four cross-bred does were used, the progeny of New Zealand White (NZW) bucks and (NZW $\times$ Californian) does. They had all previously completed one or two lactations.

\section{Procedures}

A replicate of this experiment consisted of pairs of animals in one of four physiological states: non-pregnant (NP), pregnant (P), lactating (L) or concurrently pregnant and lactating (CPL). Within each pair, animals were offered food at one of two levels of dietary metabolizable energy (ME) intake, according to a scale based on metabolic body-weight ( $\mathrm{kg}$ body-weight $\mathrm{t}^{0.75}$ ) and using the predicted ME of the diet shown in Table 1. NP and P animals were offered 450 or $600 \mathrm{~kJ} \mathrm{ME} / \mathrm{kg}$ body-weight ${ }^{0 \cdot 75}$ and $\mathrm{L}$ and CPL animals were offered 1000 or $1500 \mathrm{~kJ} \mathrm{ME} / \mathrm{kg}$ body-weight ${ }^{0.75}$. The whole experiment consisted of three complete replicates.

All animals were housed in the metabolism cages described by Spreadbury (1978). The period of pregnancy and lactation was divided into three consecutive periods of $8 \mathrm{~d}$ after animals had been allowed to adapt to their designated feeding levels for $4 \mathrm{~d}$. Urine and faeces were collected separately each day and stored at $1^{\circ}$. At the end of each $8 \mathrm{~d}$ period a subsample of urine was taken for nitrogen and energy (E) estimation and a subsample of faeces taken for dry matter (DM) determination. The remainder of faeces were stored at $-20^{\circ}$. At the end of the third period a pooled faecal sample was prepared for each doe 
with the proportions based on total DM output each week. The pooled sample was then freeze-dried before bomb calorimetry and $\mathrm{N}$ determination.

The amount of food to be offered each day was determined at the beginning of each $8 \mathrm{~d}$ period according to the observed body-weight of the doe. The actual food consumptions were then recorded daily. Each doe was placed in a metabolism cage inside a small, gradient-layer calorimeter (Pullar, 1969) for $24 \mathrm{~h}$ around the mid-point of each balance period. Thus heat-exchange measurements were made in 'early' (day 9 or 10) 'mid-' (day 17 or 18) and 'late' (day 25 or 26) pregnancy or lactation.

$\mathrm{L}$ and CPL animals were removed from their cages once daily to suckle their pups as previously described (Partridge et al. 1983) and the milk yield of the doe was estimated by her weight loss over the suckling period. All does and their litters were maintained at $16^{\circ}$ on a $14 \mathrm{~h}$ light- $10 \mathrm{~h}$ dark cycle. Litter sizes were standardized to eight pups immediately after parturition by removing pups or cross-fostering when appropriate.

\section{Milk composition}

The effects of feeding level and stage of lactation on the composition of does' milk were determined by hand-milking a parallel group of L and CPL does ( $n 8$ and 5 respectively) on days 10,18 and 26 of lactation. These animals received the same range of dietary allocations as those on the main experiment. Earlier work had shown that it was impossible to collect milk from does without disturbing their subsequent milk secretion on the day of collection. Consequently, if the experimental group of does had been sampled their milk production would have been reduced.

Samples of 15-20 g were obtained from one anterior mammary gland after the injection of 1 i.u. oxytocin into the marginal ear vein.

\section{Analytical methods}

Analysis of $\mathrm{N}$ and $\mathrm{E}$ in feed, faeces, urine and milk was made as described by Partridge et al. (1983).

\section{Statistical treatment of results}

Standard split-plot and regression analyses were used throughout, with data being pooled whenever appropriate.

\section{RESULTS}

\section{Digestibility of $N$ and $E$}

The relation between DM intake (DMI) and the digestibility of $\mathrm{N}$ and $\mathrm{E}$ was examined within and between physiological states. As DMI (g/d) increased there was a significant depression in both apparent $\mathrm{N}$ and $\mathrm{E}$ digestibilities, the slopes of the lines for the physiological states being parallel but not coincident.

The relations were described by the following equations:

$$
\text { Apparent } \mathrm{N} \text { digestibility }=\mathrm{C}-0.00051 \text { (SE 0.00011)DMI, }
$$

where $C$ is $0.90,0.87,0.96$ and 0.94 (standard error of difference (SED) 0.015 ) for NP, $\mathrm{P}$, $\mathrm{L}$ and $\mathrm{CPL}$ animals respectively.

$$
\text { Apparent E digestibility }=\mathrm{C}-0.00025 \text { (SE 0.00011) DMI, }
$$

where $\mathrm{C}$ is $0.82,0.78,0.82$ and 0.79 (SED 0.016 ) for NP, $\mathrm{P}, \mathrm{L}$ and $\mathrm{CPL}$ animals respectively.

$\mathrm{ME}$ was found to be related to digestible energy (DE) by the equations: $\mathrm{ME}=0.98$ (SE 0.007) DE (for NP and P does) and ME $=0.96$ (SE 0.004) DE (for L and CPL does). Using eqns (1) and (2) and the previously stated correction factors, it was possible to predict the 


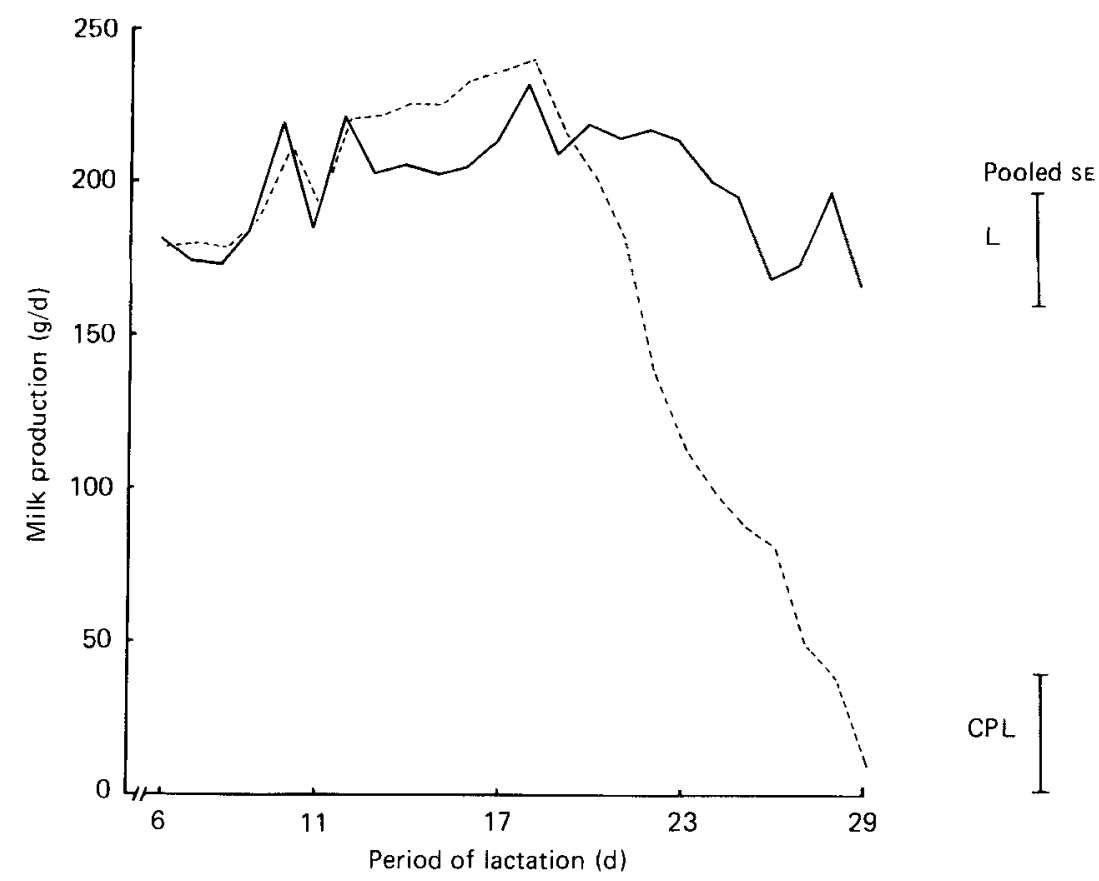

Fig. 1. The daily milk yields of lactating $(\mathrm{L}, \longrightarrow$ ) and concurrently pregnant and lactating (CPL, - - ) rabbits (day $0=$ day of parturition).

ME intake of does when in the calorimeter. There was no apparent alteration in voluntary food intake as a result of confinement in the calorimeter.

\section{Milk production}

The mean daily milk yields of $\mathrm{L}$ and CPL does are shown in Fig. 1. It is clear that although yields were similar over the first two periods (up to day 20 of lactation), thereafter the CPL does showed a sharp depression in milk output.

\section{Milk composition}

The milk composition values for $\mathrm{L}$ and CPL animals are shown in Table 2. There was no effect of level of feeding on the $\mathrm{N}$ or $\mathrm{E}$ contents of the milk and therefore mean values for each period are shown. The only significant differences between treatments were in period 3 , when the milk of CPL does had a much higher concentration of $\mathbf{N}$ and $\mathbf{E}$. This change in composition clearly paralleled the changes in milk yield which were noted previously.

There was a significant linear relation between ME intake (MEI $(\mathrm{MJ} / \mathrm{d}) ; x$ ) and milk E output $(y)$ for both $\mathrm{L}$ and CPL does over the course of lactation. Differences between the slopes and intercepts for $\mathrm{L}$ and CPL does were not significant, and overall the relation was described by the equation:

$$
\text { Milk E }=0 \cdot 28(\text { SE 0.093) MEI + 0.628 (SE 0.346), }
$$

where Milk $\mathrm{E}$ is milk $\mathrm{E}$ output $(\mathrm{MJ} / \mathrm{d})$ and the number of observations was 12.

\section{Energy exchanges in the calorimeter}

The relation between $\mathrm{MEI}$ and energy retention (ER) including milk synthesis (ER $=\mathrm{MEI}-$ heat, $\mathrm{kJ} / \mathrm{kg}$ body-weight ${ }^{0 \cdot 75}$ per $\mathrm{d}$ ) is shown in Fig. 2, and mean values for 


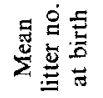

$\stackrel{\odot}{\infty}$

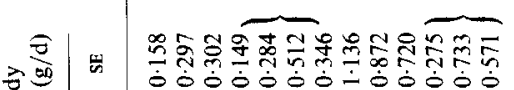

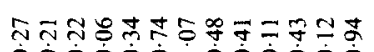

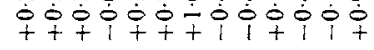

美容官

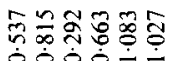

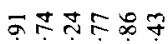

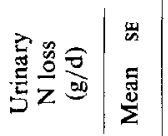

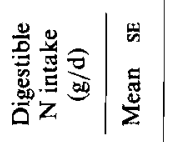

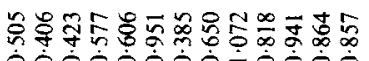

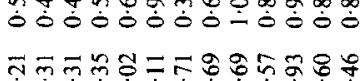

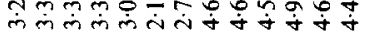

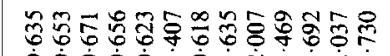
$00000-0-4-D i$

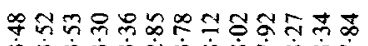

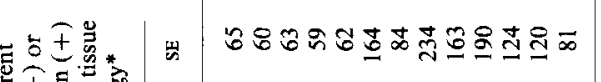

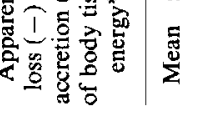

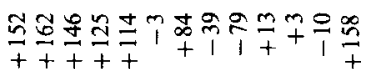

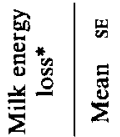

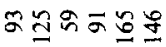

공ำ

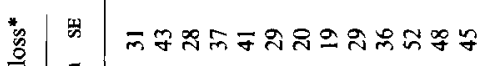
莬

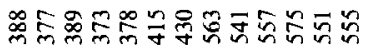

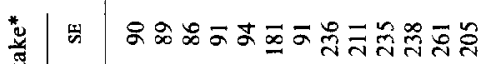

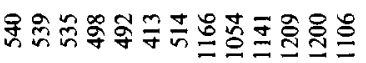

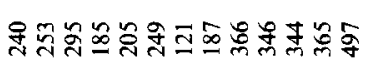

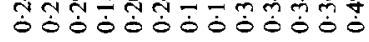

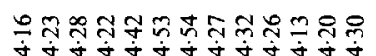




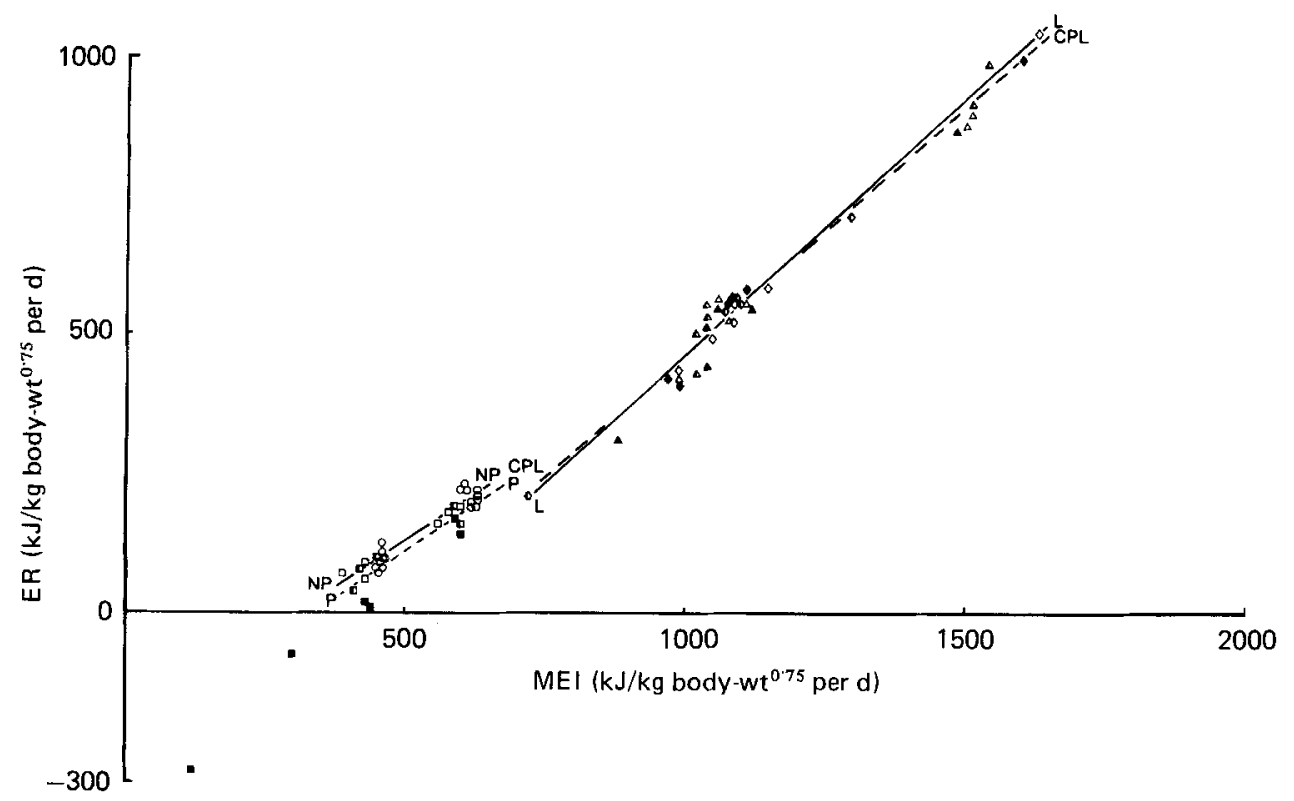

Fig. 2. The relation between metabolizable energy intake (MEI) and energy retention (ER; MEI - heat loss) for non-pregnant (NP; $O$ ), pregnant (P; early $\square$, mid- $\square$, late $\square$ ), lactating (L; early $\diamond$, mid$\diamond$, late $\bullet$ ) and concurrently pregnant and lactating (CPL; early $\Delta$, mid- $\Delta$, late $\Delta$ ) does. Lines of best fit for NP and L (-) and P and CPL (--) does are shown. For equations, see Table 4.

$\mathrm{E}$ and $\mathrm{N}$ balances are summarized in Table 3. The spread of the values was not as dispersed in $\mathrm{L}$ and CPL groups as the experimental design had intended. This was a result of reduced voluntary food intake in some animals offered the higher levels of ME. In addition, two pregnant does $(\mathrm{P})$ had reduced intakes throughout period 3 . In Table 3, therefore, the values for this period are presented both including and excluding these does.

Table 4 shows the overall regression relations of the form $\mathrm{ER}=k \mathrm{MEI}+\mathrm{C}$ derived from the values presented in Fig. 2, although excluding the two 'low' MEI values for P animals in period 3. The estimates of the regression coefficients on a between-animal basis did not differ significantly from the within-animal estimates. Subsequent analysis was therefore done on an overall basis.

Comparisons between periods were made for each of the four physiological states: NP, $\mathrm{P}, \mathrm{L}$ and CPL. These showed no significant difference between the three periods with the exception of the $\mathbf{P}$ data in period 3 , where the intercept term was significantly lower than that in periods 1 and $2(P<0.01)$. Comparisons between the relations for NP and $P$ animals showed no significant difference when the periods were combined, but when comparisons were made on a period-by-period basis the $P$ intercept was again significantly lower in period $3(P<0.01)$. For a given MEI, therefore, there is a suggestion that ER is reduced in late pregnancy, although the relation is derived from only four data points and possible trends should therefore be treated with appropriate caution. Differences between the regression relations for $\mathrm{L}$ and CPL does were also not significant, and a combined analysis is therefore shown in Table 4.

Estimates of the doe's maintenance energy requirements $\left(\mathrm{ME}_{\mathrm{m}}\right)$ can be calculated as the intake equivalent to zero $E R$. $M E_{m}$ for $N P$ and $P$ animals was therefore estimated to be $329 \mathrm{~kJ} / \mathrm{kg}$ body-weight ${ }^{0.75}$ and for L and CPL animals $475 \mathrm{~kJ} / \mathrm{kg}$ body-weight ${ }^{0.75}$. It should be emphasized that for $\mathrm{P}, \mathrm{L}$ and CPL animals these values do not represent the $\mathrm{E}$ 
Table 4. Regression relations of the form $E R=k M E I-C$, where $E R$ is energy retention (metabolizable energy intake (MEI)-heat), $\mathrm{k}$ is the apparent efficiency of dietary metabolizable energy utilization and $C$ is a constant. All values in $\mathrm{kJ} / \mathrm{kg}$ body-weight ${ }^{0.75}$

\begin{tabular}{llcc}
\hline $\begin{array}{c}\text { Physiological } \\
\text { state }\end{array}$ & Regression & RSD & $\begin{array}{c}\text { No. of } \\
\text { observations }\end{array}$ \\
NP & ER $=0.67$ (SE 0.057) MEI-208 & 19.4 & 18 \\
P* & ER $=0.67$ (SE 0.095) MEI-224 & 30.5 & 15 \\
NP+P* & ER $=0.69$ (SE 0.054) MEI-227 & 25.8 & 33 \\
L & ER $=0.90($ SE 0.022) MEI -441 & 19.1 & 17 \\
CPL & ER $=0.85($ SE 0.036) MEI -387 & 33.8 & 18 \\
L+CPL & ER $=0.87$ (SE 0.021) MEI-413 & 27.3 & 35 \\
\hline
\end{tabular}

$\mathrm{NP}$, non-pregnant; $\mathrm{P}$, pregnant; $\mathbf{L}$, lactating; $C P L$, concurrently pregnant and lactating.

* Excluding values for two does with very low voluntary food intakes, see p. 204.

requirement for maintenance of maternal tissue alone but include a component of $\mathrm{E}$ requirement for conceptus growth (P), milk energy output (L) or both (CPL).

The partial efficiency of energy utilization for $L$ and CPL does $(87 \%$, Table 4$)$ was very high, and undoubtedly close to the theoretical maximum efficiency of $E$ storage for this type of diet. There was a distinct difference, however, between the partitioning of dietary ME in CPL and $\mathrm{L}$ does in period 3. During this period of late pregnancy, CPL does partitioned $M E$ away from milk production towards body $\mathrm{E}$ accretion (maternal + fetal, $158 \mathrm{~kJ} / \mathrm{kg}$ body-weight ${ }^{0 \cdot 75}$ per d, see Table 3 ).

Multiple-regression analyses were performed on the values for $L$ and CPL does which were apparently mobilizing body tissues for milk production, i.e. those in negative tissue $\mathrm{E}$ balance in periods 1, 2 or 3 . When milk $\mathrm{E}$ output (Milk $\mathrm{E}$ ) was the dependent variable and MEI and body ER the independent variables, the relation was described by the following equation:

$$
\text { Milk E }=0.94 \text { (SE 0.071) MEI - 0.94 (SE 0.111) body ER - } 469 \text { (RSD 26 } 1 \text { ) }
$$

where all factors are expressed in $\mathrm{kJ} / \mathrm{kg}$ body-weight $\mathrm{t}^{0.75}$ ( $n$ 19).

The partial regression coefficient for body ER indicates the efficiency of conversion of this energy to milk, i.e. 94\%, identical to the value estimated by Partridge et al. (1983). Our estimate of MEI at zero milk output and zero body ER is therefore $499 \mathrm{~kJ} / \mathrm{kg}$ body-weight $\mathrm{t}^{0 \cdot 75}$ per d.

\section{$N$ balance}

$\mathrm{N}$ accretion was markedly increased in late pregnancy in $\mathrm{P}$ and CPL does (Table 3). In NP animals approximately 0.07 of the digestible $\mathrm{N}$ intake was apparently accreted into body tissue, whereas in $\mathrm{P}$ does this value rose fourfold to $\mathbf{0} 28$. With the shift away from milk synthesis in period 3 in CPL does, milk $N$ loss decreased and body tissue $N$ gain (maternal + fetal) increased.

\section{DISCUSSION}

There was a gradual fall in the does' voluntary food intake in late pregnancy, as has been documented by other authors (Lebas, 1975; Reyne et al. 1977). In the experimental design, day 25 of pregnancy was chosen in an attempt to avoid this decline while the does were in the calorimeter. Clearly in the case of two animals this was not achieved (see Fig. 2). Other studies at the Rowett Research Institute (G. G. Partridge, unpublished results) have 
shown that pregnant does offered a diet of high energy density (14.2 $\mathrm{MJ} \mathrm{ME} / \mathrm{kg} \mathrm{DM})$ to appetite show an immediate increase in voluntary food intake for the first week of pregnancy and thereafter a gradual decline until parturition about day 32 . It is possible that in does accreting body fat during pregnancy, some form of feedback mechanism is in operation adjusting subsequent dietary $E$ intake according to the degree of fat deposition. The depression in intake appears much too early to be associated with increases in conceptus size and resultant competition with the gastrointestinal tract for space within the abdominal cavity.

The observed decline in milk production of CPL does in late pregnancy (Fig. 1) confirms the observations of Lebas (1972). This period coincides exactly with the curvilinear rise in fetal growth in the rabbit (Hudson \& Hull, 1975), although the underlying hormonal mechanisms responsible for this pronounced shift in the partitioning of $E$ remain to be determined. The milk composition values for $\mathrm{L}$ does agree closely with those reported in an earlier study when fat-supplemented diets were given to lactating animals (Partridge et al. 1983).

Our overall value for the apparent efficiency of dietary ME utilization $(k)$ of 0.69 for NP rabbits (Table 4) falls in line with several reported values for pigs in their thermoneutral zone when fed on cereal-based diets (see recent summary by Close et al. 1985, Table 3). However, our experimental ration contained $18 \%$ of its gross energy in the form of fat, and consequently we might have expected a slightly higher value for $k$ because of the inherently higher biochemical efficiency of translocation of dietary fat into tissue fat. In the absence of slaughter values, however, it is clearly impossible to partition this retained $\mathrm{E}$ into maternal and reproductive components.

Our estimate of $\mathrm{ME}_{\mathrm{m}}$ for $\mathrm{NP}$ and $\mathrm{P}$ rabbits $\left(329 \mathrm{~kJ}\right.$ body-weight $\left.{ }^{0.75} / \mathrm{kg}\right)$ is lower than that found by Eriksson (1952) using indirect calorimetry techniques. He found that NP, individually caged does of the Small Chinchilla breed ( $3 \mathrm{~kg}$ mature body size) had an estimated $\mathrm{ME}_{\mathrm{m}}$ of $385 \mathrm{~kJ} / \mathrm{kg}$ body-weight ${ }^{0.75}$. The discrepancy between studies could reflect inherent breed differences in $\mathrm{ME}_{\mathrm{m}}$ such as those found for fasting heat production by Lee (1939). He obtained values of approximately 250 and $270 \mathrm{~kJ} / \mathrm{kg}$ body-weight $t^{0.75}$ for Polish $(\sim 1.3 \mathrm{~kg})$ and NZW $(4 \mathrm{~kg})$ breeds respectively, a between-breed difference of $8 \%$.

The overall value of $k$ during lactation in $\mathrm{L}$ and CPL does $(0 \cdot 87$, Table 4$)$ was higher than that estimated by Partridge et al. (1983) $(k 0 \cdot 76)$. This difference presumably relates to differences in diet composition between the two studies, particularly with respect to dietary fat content. The gross energy of the diet used in the present study, containing both vegetable oil and full-fat soya-bean meal, was $21.46 \mathrm{MJ} / \mathrm{kg} \mathrm{DM}$ compared with $18.67 \mathrm{MJ} / \mathrm{kg} \mathrm{DM}$ in the earlier experiment.

If we assume theoretical biochemical efficiency values of $95 \%$ for the translocation of dietary fat to tissue-milk fat, $80 \%$ for dietary carbohydrate to tissue-milk fat plus lactose, and $80 \%$ for dietary amino acids to tissue-milk protein, we obtain a theoretical value for $k$ of approximately 0.84 for the diet used in the present study. Our determined value is therefore on or slightly above this theoretical maximum. It should be remembered, however, that ER is a function of all substrates available to the mammary gland during lactation and most of our does were mobilizing body fat to support milk synthesis, especially in early and mid-lactation (see mean apparent loss or accretion of body tissue $\mathbf{E}$ values, Table 3 ). This fat mobilization will thus tend to increase the $k$ value to a certain degree. The only other obvious instance in which $k$ approaches unity is when animals are kept in cool conditions where there is a substitution of the heat increment of feeding for the extra thermoregulatory heat that is required to satisfy the increased environmental demand (see Mount, 1979). All does in the present experiment were maintained at $16^{\circ}$, and therefore it seems unlikely that there was a conflicting effect of ambient temperature on the heat 
increment at the levels of feeding used in pregnancy or lactation. The estimates of $M E_{m}$ for the two Rowett Research Institute studies also differed, by around $11 \%$ ( $\mathrm{L}$ and CPL, $475 \mathrm{~kJ} / \mathrm{kg}$ body-weight ${ }^{0.75}$ compared with $424 \mathrm{~kJ} /$ body-weight $^{0.75}$ in the earlier study). There were slight breed differences, however, which could explain some of the variation; cross-bred does in the present experiment being $0.75 \mathrm{NZW}-0.25$ Californian rather than $0.5 \mathrm{NZW}-0.5$ Californian as in the earlier study. Unfortunately, at present there appears to be no published information on any possible differences in $\mathrm{ME}_{\mathrm{m}}$ between these two main meat breeds and their hybrids.

The authors would like to thank Dr A. C. Brewer for statistical analysis of the results and Susan Allan and Alexmary Connell for technical help.

\section{REFERENCES}

Close, W. H., Noblet, J. \& Heavens, R. P. (1985). British Journal of Nutrition 53, 267-279.

Eriksson, S. (1952). Kungliga. Lantbrukshögskolans Annaler 19, 7-108.

Hudson, D. G. \& Hull, D. (1975). Biology of the Neonate 27, 71-79.

Lang, J. (1981). Nutrition Abstracts and Reviews, Series B 51, 197-225, 287-302.

Lebas, F. (1972). Annales Zootechnie 21, 129-131.

Lebas, F. (1975). Annales Zootechnie 24, 267-279.

Lee, R. C. (1939). Journal of Nutrition 18, 473-500.

Mount, L. E. (1979). Adaptation to Thermal Environment. London: Edward Arnold.

National Research Council (1977). Nutrient Requirements of Rabbits. Washington, DC: National Academy of Sciences.

Partridge, G. G. \& Allan, S. J. (1982). Animal Production 35, 145-1 55.

Partridge, G. G., Allan, S. J., Findlay, M. \& Corrigall, W. (1984). Animal Production 39, 465-472.

Partridge, G. G., Fuller, M. F. \& Pullar, J. D. (1983). British Journal of Nutrition 49, 507-516.

Pullar, J. D. (1969). In International Encyclopaedia of Food and Nutrition, vol. 17, Nutrition of Animals of Agricultural Importance, part 1, pp. 471-490 [D. P. Cuthbertson, editor]. Oxford: Pergamon Press.

Reyne, Y., Prud'hon, M., Debicki, A.-M. \& Goussopoulos, J. (1977). Annales Zootechnie 27, $211-223$.

Spreadbury, D. (1978). British Journal of Nutrition 39, 601-613. 